\title{
ASSESSMENT OF THE LEVEL OF FINANCIAL SECURITY OF MACHINE-BUILDING ENTERPRISES OF ZAPORIZHZHIA REGION WITH THE HELP OF INTEGRAL-RATING METHOD
}

\author{
Lina Khudoliei \\ Department of Finance, Banking and Insurance \\ Zaporizhzhia National University \\ 66 Zhukovskogo str., Zaporizhzhia, Ukraine, 69600 \\ lina_kozobash@ukr.net
}

\begin{abstract}
In the deepening of the financial crisis, enterprises are trying to implement an effective anti-crisis policy. The financial system as a source of accumulation of modern crisis phenomena, which are spreading further to all spheres of the economy, generally require the formation of new instruments to ensure their financial and economic security. The constant increase in the riskiness of economic activity may entail a significant decrease in the level of financial stability and solvency of the enterprise, and in the future lead to bankruptcy, and requires each business entity to create a perfect system of financial and economic security.

To assess the financial security situation at specific enterprises, not all financial and economic indicators that are used can be applied, but only those that most closely meet the requirements and most reflect the results of financial and economic activity, and, if possible, do not contradict each other.

The modern business environment highlights the issues of ensuring financial and economic security. Proper assessment of it, as well as diagnostics of the financial condition of enterprises is a priority task for ensuring sustainable development and operation of the enterprise.

Market conditions require enterprises to improve production efficiency, competitiveness of products and services based on the implementation of scientific and technological progress, effective forms of management and enterprise management, enterprise activation and so on. So, the role of diagnostics of a financial condition is great enough.

Diagnostics of the financial security of an enterprise is an analytical assessment of all the functional components of safety from the standpoint of achieving the highest possible level of protection against internal and external threats, aimed at making effective management decisions and developing a financial security strategy.

With the help of diagnostics of the company's financial security, the article will assess the level of financial security of machine-building enterprises in the Zaporizhzia region using the integrated-rating method.

Keywords: diagnostics, financial security, enterprise, method, analysis, indicators, assessment.
\end{abstract}

\section{Introduction}

One of the tools for successfully forecasting and managing the level of financial security of an enterprise is the diagnosis of its financial condition.

Given the high degree of uncertainty that is an integral companion of any economic system at the stage of development of market relations, the high speed of financial transactions, the complexity of the conditions for the functioning of business entities, there is a need to adapt, improve, and develop the foundations for diagnosing the financial security of machine building enterprises. In the teaching and methodological literature, the concept of "financial diagnosis" is generally identified with financial analysis or considered as its component or species.

With the help of diagnostics it becomes possible in the channel of development of this particular direction not only to track the state of the object at each time interval, but also to identify its state in order to control it. It is worthwhile to clarify that diagnostics do not replace the control function - analysis, but essentially complements it.

In the economic theory and law theory, various concepts of security have been developed, in particular, in the management of economic systems. It should be noted that the category of economic security is treated differently in the scientific literature [2-4]. Thus, in the opinion of [4], "... under the economic security of the system, it is necessary to understand the set of properties of 
the state of its production subsystem, which provides the possibility of achieving the goal by the whole system." [3] believes that "... economic security is a system to protect the vital interests of the state. Objects of protection at the same time can act: the economy of the country as a whole, certain regions, spheres and sectors of the economy, legal entities and individuals. According to [2] "... economic security is a state of the economic system that allows it to develop dynamically, effectively and solve social problems, and in which the state has the ability to produce and enforce an independent economic policy."

After analyzing the given definitions, let's provide our own interpretation of this indicator. So, the financial and economic security of the enterprise is constant maintenance at the enterprise increase of a level of financial and economic indicators, effective management of the finance by creation of necessary preconditions of protection of the enterprise from external and internal threats.

Analysis of approaches to diagnosing the level of financial security of the enterprise shows that this problem has not yet been sufficiently investigated. Thus, there are no sufficiently substantiated criteria for the level of financial security, the formation of which can be carried out after the development of a typology of possible states of the enterprise's security on the basis of the classification of financial security factors of the enterprise.

\section{Aim of research}

Assessment of the financial security of machine-building enterprises in the Zaporizhzhia region using the integrated-rating method.

\section{Materials and methods of research}

In the process of research, the following methods are used to achieve the goal: analysis, comparison, calculation, theoretical generalization.

The information and statistical base of the research is the scientific achievements of Ukrainian scientists on this subject, the official data of the annual reports of the research enterprises for 2012-2016.

\section{Results of research}

Ensuring financial security involves the allocation, analysis and assessment of existing threats for each of the functional components and the development on their basis of a system of measures that prevent and counteract the emergence of crisis phenomena in the enterprise.

The main requirements for the model of financial security are:

- it should reflect the general features of financial security;

- be adequate and should produce results that are close to real;

- to enable the use of the model for making managerial decisions;

- to provide the possibility of comparing several enterprises.

In addition, the model should be implemented in a certain, preferably available software product, and when changing the input data, it must correctly generate a response to the assigned tasks.

However, the presence of a large number of initial indicators complicates the procedure for analyzing financial security, makes it cumbersome, reduces its informativeness and negatively affects the importance of weighting factors. To solve this problem, it is suggested to use the sequential convolution procedure, in which the initial indicators are first grouped into four groups according to a certain characteristic. For each group, a generalized indicator is defined that contains a number of calculated baseline indicators.

Adequate mathematical models for the management of financial security require a comprehensive consideration of uncertainties associated with the features of the functioning of enterprises in modern market conditions:

- target conditions (availability of qualitatively defined decision-making goals, psychologig cal aspects of human acceptance of the proposed solutions);

- simulated objects and subject areas (conflict nature, availability of expert information, describes the object, restrictions on resources); 
- initial and current information about the occurring processes (contradictions, inaccurar cies, fuzziness, ambiguity).

There are a significant number of methods in which various analytical formulas are used to calculate the valuation of individual properties and to comprehensively assess the level of financial security.

One of the most convenient ways to construct a generalized response is the Harrington desirability function. The construction of this function is based on the idea of converting the natural values of private responses into a dimensionless scale of desirability or advantages. The desirability scale refers to psychophysical scales, the purpose of which is establishment of a correspondence between physical and psychological parameters. By physical parameters are understood various responses characterizing the functioning of the investigated object.

The choice of indicators is due to the fact that all indicators in the complex should determine the financial security of the enterprise. Factors of the financial security of the company are ordered on the basis of an expert method (the employees of the economic department of the enterprises studied were sent questionnaires for the expert assessment to determine the main indicators of the financial security of enterprises, then taking into account these questionnaires, and a group of financial safety factors was formed). As a result, the following indicators of the financial security factors of the enterprise were selected: liquidity; financial sustainability; profitability; business activity.

Financial security of the enterprise $(\mathrm{Y})$ can be estimated on the basis of values of generalized groups of indicators (factors) (Table 1):

$$
\mathrm{Y}=\mathrm{f}_{\mathrm{Y}}\left(\mathrm{X}_{1}, \mathrm{X}_{2}, \mathrm{X}_{3}, \mathrm{X}_{4}\right)
$$

where $\mathrm{X}_{\mathrm{i}}-$ the corresponding $\mathrm{i}$-th group of exponents.

Table 1

Groups of indicators (factors) of financial security of the enterprise

\begin{tabular}{|c|c|c|c|}
\hline Groups of indicators & & Indicators & \\
\hline \multirow{5}{*}{$\begin{array}{l}\text { Indicators of financial } \\
\text { sustainability }\end{array}$} & \multirow{6}{*}{$\mathrm{X}_{1}$} & Coefficient of stability of economic growth & $X_{11}$ \\
\hline & & Concentration factor of borrowed capital & $\mathrm{X}_{12}$ \\
\hline & & Coefficient of financial stability & $X_{13}$ \\
\hline & & Coefficient of financial stability (financing) & $X_{14}$ \\
\hline & & The coefficient of financial independence (autonomy) & $\mathrm{X}_{15}$ \\
\hline \multirow{4}{*}{$\begin{array}{c}\text { Indicators of solvency and } \\
\text { liquidity }\end{array}$} & & Coefficient of maneuverability of equity capital & $X_{16}$ \\
\hline & \multirow{3}{*}{$X_{2}$} & Absolute liquidity ratio & $\mathrm{X}_{21}$ \\
\hline & & Coefficient of quick liquidity & $X_{22}$ \\
\hline & & Total liquidity ratio & $X_{23}$ \\
\hline \multirow{3}{*}{ Indicators of receivables } & \multirow{3}{*}{$X_{3}$} & Ratio of own capital turnover & $X_{31}$ \\
\hline & & Asset turnover ratio & $X_{32}$ \\
\hline & & Accounts receivable turnover ratio & $X_{33}$ \\
\hline \multirow{4}{*}{$\begin{array}{l}\text { Indicators of profitability and } \\
\text { solvency }\end{array}$} & \multirow{4}{*}{$X_{4}$} & Profitability of capital (assets) by net profit & $X_{41}$ \\
\hline & & Profitability of equity capital & $X_{42}$ \\
\hline & & Profitability of production assets & $X_{43}$ \\
\hline & & Profitability of sales on net profit & $\mathrm{X}_{44}$ \\
\hline
\end{tabular}



factors:

The integrated value of each of these groups of indicators can be calculated by the following

$$
X i=f_{i}\left(X_{i 1}, \ldots, X_{i j}\right), i=1, N, j=1, M \text {, }
$$

where $\mathrm{N}$ - the number of generalized groups $(\mathrm{N}=4) ; \mathrm{M}-$ the number of indicators in a group.

The presented set of indicators is one of the possible variants and can be formed by the expert individually for each individual enterprise taking into account its specificity.

The enterprises of the Zaporizhzhia region will determine the values of performance indicators, which in the future we use to build the model.

After the values of the parameters characterizing certain aspects of the financial state of the investigated enterprise have been obtained, they must be reduced to a dimensionless form. The normalized value of the $\mathrm{i}$-th indicator is calculated by the formula:

$$
\tilde{x}_{i}=\frac{x_{i}-x_{i}^{\min }}{x_{i}^{\max }-x_{i}^{\min }}, \quad i=1, n .
$$

In the future, let's determine the importance of groups and individual indicators, for which let's use the Fishburn rule [9], which reflects the fact that nothing is known about the significance level of indicators except their importance relative to each other.

Let's determine the significance of each indicator in accordance with the strategy of the enterprise or the main objectives of its activities, assigning the corresponding ratings to the indicators. Let's put in correspondence to each exponent $\mathrm{Xj}$ the level of its significance ri for analysis. To assess this level, it is necessary to arrange all the indicators in descending order of significance in such way that the rule is fulfilled:

$$
\mathrm{r}_{1} \geq \mathrm{r}_{2} \geq \mathrm{r}_{\mathrm{n}}
$$

If the system of indicators is ranked in order of decreasing importance, then the importance of the i-th index will be determined in accordance with the Fishburn rule:

$$
r_{i}=\frac{2(\mathrm{~N}-\mathrm{i}+1)}{(\mathrm{N}+1) \mathrm{N}}, \mathrm{i}=1, \mathrm{~N},
$$

where $r_{i}$ - the significance of the corresponding factor, $\mathrm{N}$ - the total number of factors, $\mathrm{i}$ - the place in the rank of a separate indicator.

Then the estimate (9) corresponds to the maximum entropy of the available information uncertainty about the object of research, that is, it allows to make better estimates in a bad information situation.

In accordance with this, let's obtain the following results (Table 2). In this case, let's assume that all the indicators in the groups are equivalent to each other, that is, the weight coefficients for them will be the same:

$$
\mathrm{r}_{\mathrm{ji}}=1 / \mathrm{M}, \mathrm{i}=1, \mathrm{~N}, \mathrm{j}=1, \mathrm{M} \text {. }
$$

Calculations of the weight coefficients of groups and individual indicators are given in Table 2.

In the future, let's calculate the group generalizing exponents of the i-th group in the non-universal form $\left(\mathrm{G}_{\mathrm{i}}\right)$ by the formula:

$$
\mathrm{G}_{\mathrm{i}}=\sum_{\mathrm{i}} \omega_{\mathrm{i}} \widetilde{\mathrm{x}_{\mathrm{i}}}, \mathrm{i}=1, \mathrm{~m},
$$

where $\omega_{i}-$ weight coefficients. 
The group summary indicators are calculated in Table 3.

Table 2

Weights for financial security indicators

\begin{tabular}{|c|c|c|c|}
\hline Name of the group & $\begin{array}{l}\text { Weight of the } \\
\text { group }\end{array}$ & Indicators, $\mathrm{x}_{\mathrm{i}}$ & $\begin{array}{c}\text { Weight of } \\
\text { the indicators, } \omega_{i}\end{array}$ \\
\hline \multirow{5}{*}{$\begin{array}{l}\text { Indicators of financial } \\
\text { sustainability }\end{array}$} & \multirow{5}{*}{0,4} & Coefficient of stability of economic growth & 0,08 \\
\hline & & Concentration factor of borrowed capital & 0,08 \\
\hline & & Coefficient of financial stability & 0,08 \\
\hline & & Coefficient of financial stability (financing) & 0,08 \\
\hline & & The coefficient of financial independence (autonomy) & 0,08 \\
\hline \multirow{3}{*}{$\begin{array}{l}\text { Indicators of solvency } \\
\text { and liquidity }\end{array}$} & \multirow{3}{*}{0,3} & Coefficient of maneuverability of equity capital & 0,1 \\
\hline & & Absolute liquidity ratio & 0,1 \\
\hline & & Coefficient of quick liquidity & 0,1 \\
\hline \multirow{3}{*}{$\begin{array}{l}\text { Indicators of } \\
\text { receivables }\end{array}$} & \multirow{3}{*}{0,2} & Total liquidity ratio & 0,07 \\
\hline & & Ratio of own capital turnover & 0,07 \\
\hline & & Asset turnover ratio & 0,07 \\
\hline \multirow{4}{*}{$\begin{array}{l}\text { Indicators of profitabil- } \\
\text { ity and solvency }\end{array}$} & \multirow{4}{*}{0,1} & Accounts receivable turnover ratio & 0,025 \\
\hline & & Profitability of capital (assets) by net profit & 0,025 \\
\hline & & Profitability of equity capital & 0,025 \\
\hline & & Profitability of production assets & 0,025 \\
\hline
\end{tabular}

Table 3

Group summary indicators

\begin{tabular}{lcccccc}
\hline No. & \multicolumn{3}{c}{ Period } \\
& Indicator & 2012 & 2013 & 2014 & 2015 & 2016 \\
\hline
\end{tabular}

PJSC «Zaporizhzhia plant of heavy crane building»

2

Indicators of profitability
Indicators of profitability and solvency
Indicators of solvency and liquidity
Indicators of business activity

Indicators of profitability and solvency Indicators of solvency and liquidity Indicators of business activity

Indicators of profitability Indicators of profitability and solvency Indicators of solvency and liquidity Indicators of business activity

Indicators of profitability Indicators of profitability and solvency Indicators of solvency and liquidity Indicators of business activity

$\begin{array}{cc}1 & 0,731183 \\ 1 & 0 \\ 0,793103 & 0,586207 \\ 1 & 0,741504\end{array}$

0
0,755329
0
0

0,44086

0,924731

0,811863

0,840593

PJSC „Zaporizhtransformator”

$\begin{array}{ccccc}1 & 0,904324 & 0,125852 & 0,079694 & 0,578731 \\ 0,190657 & 0,26449 & 0,188561 & 0,277972 & 0,08 \\ 0,26 & 0,179007 & 0,071213 & 0,01452 & 0,1 \\ 0,006087 & 0,048244 & 0,056413 & 0,017867 & 0,21\end{array}$

$\mathrm{NPO}$ «Energomash»

$\begin{array}{ccccc}0,25 & 0,344662 & 0,326217 & 0,879286 & 0,711959 \\ 0,171006 & 0,129925 & 0,093333 & 0,313333 & 0,303197 \\ 0,191384 & 0,168738 & 0,027039 & 0,101122 & 0,009841 \\ 0,013822 & 0,035797 & 0,02512 & 0,085087 & 0,152108\end{array}$

PJSC „Berdyansk reapers

$\begin{array}{ccccc}0 & 0,037 & 1 & 0,683 & 0,340 \\ 0,201 & 0,203 & 0,267 & 0,273 & 0,181 \\ 0,3 & 0,039 & 0,008 & 0,009 & 0,008 \\ 0,033 & 0,005 & 0,004 & 0,0122 & 0,21\end{array}$


The assessment of financial security is one of the most difficult problems, because it is necessary to take into account a large number of input parameters $\mathrm{X}$, output parameters $\mathrm{Y}$ and the function of their transformation $\mathrm{Z}: \mathrm{X} \rightarrow \mathrm{Y}$. In such situation, it is expedient to solve similar problems by converting a complex function into a series of simple, consistently identify certain parameters in the functions of higher levels.

Assessment of the financial security of the enterprise is implementation of a number of functions. First, to assess the financial security of an enterprise, it is necessary to determine certain criteria for classifying an enterprise to a specific level of financial security. Secondly, the need to take into account the set of parameters that are the basis for calculating the estimated parameters.

The peculiarity of such mathematical model is that it takes into account:

- a set of initial input parameters, which is determined by means of the corresponding rer porting of the enterprise;

- a set of estimated financial condition parameters;

- the function of converting the initial parameters into valuation parameters;

- a set of decomposition functions for the coagulation of parameters, by which the level of financial security of an enterprise is identified.

To define functions, it is necessary to form sets of input and output parameters. These sets should cover a wide range of influencing parameters, as well as satisfy the conditions of completeness, efficiency and minimality.

The path to a single parameter of optimization often lies through generalization. A real process requires simultaneous consideration of several parameters that can be generalized and used as a function of the set of properties of the investigated object. Today, there are a large number of methods in which various analytic formulas are used to calculate the estimates of individual properties and complex estimates. In our opinion, it is advisable to pay attention to the desirability functions.

Today desirability functions are successfully used as optimization models in many branches of science, in particular in works [7-9].

The idea of using the desirability function as an optimizing function is that the value of each of the estimated optimization parameters (prediction) $Y_{i}$, which can be sufficiently large in the problem, is converted to the corresponding desirability $\mathrm{d}_{\mathrm{i}}$, after which a generalized desirability function D is formed, which is the geometric mean desirability individual optimization parameters [7].

The desirability scale is defined in the range from 0 to 1 . In this case, the values of the factors most favorable for the normal functioning of the system are compared by values close to 1 (from 0.6 to 1). The same levels of the factor, which are considered unfavorable, are determined on the desirability scale values close to 0 (from 0 to 0.4 ). The specific means for implementing the desirability function can be quite diverse.

For the diagnosis of financial security, let's use the Harrington desirability function [7, 9], which is a quantitative, unambiguous, unique and universal indicator of the quality of the investigated object, and if let's add qualities such as adequacy, efficiency, and statistical sensitivity, it becomes clear that it can be used as an optimization criterion:

$$
\begin{aligned}
& D=\sqrt[3]{d_{1} \cdot d_{2} \cdot \ldots \cdot d_{k}}, \\
& d i=\exp (-\exp (-G i))
\end{aligned}
$$

where $\mathrm{k}$ - the number of indicators used for assessment; $\mathrm{d}_{\mathrm{i}}$ - a particular function defined in accordance with the Harrington scale; $\mathrm{G}_{\mathrm{i}}$ - group generalizing exponents of the $\mathrm{i}$-th group in the non-virtual form.

To construct the generalized Harrington desirability function, it is necessary to convert the response values into a dimensionless desirability scale. The construction of a desirability scale that establishes the relationship between the response value and the corresponding value of the particular desirability function is basically subjective, reflecting the investigator's attitude. 
For qualitative assessment of all levels of economic parameters, let's define the linguistic variable "Indicator level", the set of values of which will be represented by the following subsets:

1. Financial danger ("FD") - an enterprise is characterized as having very low financial stability, it is on the verge of bankruptcy.

2. Unsustainable financial security ("U") - situation in which there is a violation of solvent cy, but it remains possible to replicate the balance of payment instruments and payment obligations by attracting temporarily free sources of funds into the turnover of the enterprise.

3. Normal financial security ("N") - the enterprise is characterized by an average financial stability.

4. High financial security (" $\mathrm{H}$ ") - the enterprise is characterized by high financial stability, has a high margin of competitiveness.

5. Absolute financial security ("A") - financial condition of the enterprise is stable, so rapr idly developing, characterized by a sufficiently high level of solvency in comparison with other enterprises.

The Harrington scale is conditionally divided into five sections that correspond to the above variables of financial security and characterizes the dimensionless value of the considered indicators. The point with the coordinates $(0.00 ; 0.37)$ is the critical point of inflection of desirability - it divides the values of the indicators into satisfactory and unsatisfactory (Table 4).

Table 4

Grades of investment attractiveness depending on the values of the desirability function

\begin{tabular}{cc}
\hline Function value & Characteristics of the financial security level \\
\hline $1,00-0,81$ & Absolute financial security $(« \mathrm{~A} »)$ \\
$0,80-0,64$ & High financial security $(« \mathrm{H} »)$ \\
$0,63-0,38$ & Normal financial security $(\ll \mathrm{N} »)$ \\
$\mathbf{0 , 3 7 - 0 , 2 1}$ & Unsustainable financial security $(« \mathrm{U} »)$ \\
$0,20-0,00$ & Financial danger $(« \mathrm{FD} »)$
\end{tabular}

In practical implementation of the proposed methodology, it should be considered a simplification that the choice of financial coefficients is not always unambiguous.

Let's calculate the corresponding values of the desirability function (12) and determine the level of financial security in accordance with the scale of assessments of the machine building enterprises of the Zaporizhzhia region. The results are shown in Table $\mathbf{5}$.

Table 5

Assessment of the financial security level

\begin{tabular}{|c|c|c|c|c|c|c|}
\hline \multirow{2}{*}{ No. } & \multirow{2}{*}{ Enterprise } & \multicolumn{5}{|c|}{ Period } \\
\hline & & 2012 & 2013 & 2014 & 2015 & 2016 \\
\hline \multirow{2}{*}{1} & \multirow{2}{*}{$\begin{array}{l}\text { PJSC «Zaporizhzhia plant of } \\
\text { heavy crane building» }\end{array}$} & 0,075 & 0,175 & 0,278 & 0,129 & 0,097 \\
\hline & & $(« \mathrm{FD} »)$ & $(« \mathrm{FD} »)$ & $(« U »)$ & $(« \mathrm{FD} »)$ & $(« \mathrm{FD} »)$ \\
\hline \multirow{2}{*}{2} & \multirow{2}{*}{ PJSC „Zaporizhtransformator” } & 0,211 & 0,222 & 0,327 & 0,330 & 0,272 \\
\hline & & $(« U »)$ & $(« U »)$ & $(« U »)$ & $(« U »)$ & $(« U »)$ \\
\hline \multirow{2}{*}{3} & \multirow{2}{*}{ NPO «Energomash» } & 0,309 & 0,303 & 0,322 & 0,225 & 0,248 \\
\hline & & $(« U »)$ & $(« U »)$ & $(« U »)$ & $(« U »)$ & $(« U »)$ \\
\hline \multirow{2}{*}{4} & \multirow{2}{*}{ PJSC «Berdyansk reapers» } & 0,316 & 0,341 & 0,221 & 0,265 & 0,298 \\
\hline & & $(« U »)$ & $(« U »)$ & $(« U »)$ & $(« U »)$ & $(« U »)$ \\
\hline
\end{tabular}

Consequently, the level of financial security of machine building enterprises in the Zaporizhzhia region during 2012-2016 is characterized by a low level. 
Based on the obtained value of the generalized desirability function, it is possible to construct a regression equation, to obtain the predicted value of this indicator for the future period and to predict the level of financial security for the forthcoming period.

\section{Discussion}

The ability to diagnose a financial condition allows an enterprise to maintain its sustainable development. Further development deserves the formation of a system for diagnosing the financial condition of the enterprise as a practical part that must be implemented at each enterprise to systematize and improve the efficiency of the diagnostic process.

In the group of indicators (factors) that determine the state of financial and economic security, let's propose to include the indicators of the property state of the enterprise, since for enterprises the state of fixed assets becomes very important. One of the most problematic indicators for assessing the property status in Ukraine is the depreciation rate of fixed assets. That is why it is important for assessing the level of the financial component in the system of economic security of the enterprise. In addition, it is necessary to include in the methodology the coefficient of renewal of fixed assets, which characterizes the policy of managing the property state of the enterprise.

\section{Conclusions}

So, in the process of implementing the model:

- a table with financial security input data is generated;

- a calculation table is constructed with the ones defined in the modeling of financial secue rity for each research object;

- calculation of standardized values of financial security indicators;

- for the transition to the calculation of group generalizing indicators by additive convolut tion, the calculation of the weight coefficients by the Fishburn rule is carried out;

- the integral indicator is calculated by using Harrington generalized desirability function, which allows the numerical quality of the object to match the verbal value of desirability.

\section{References}

[1] Akhnazarova, S. L., Gordeev, L. S. (2003). Use of Harrington's desirability function in solving optimization problems of chemical technology. Moscow, 76.

[2] Bandurka, O. M., Dukhov, V. E., Petrova, K. Ya., Chervyakov, I. M. (2003). Fundamentals of Economic Security. Kyiv: Publishing house of the National University of Internal Affairs, 236.

[3] Blank, I. A. (2004). Upravlenie finansovoi bezopasnost'iu predpriiatiia [Financial management of the enterprise security]. Kyiv: Nika-Centr, Iel'ga, 784.

[4] Vasyl'tsiv, T. H., Voloshyn, V. I.; Vasyl'tsiv, T. H. (Ed.) (2012). Financial and economic security of Ukraine: Strategies and mechanisms to ensure: the monograph. Lviv: Liha-Pres, 386. Available at: http:// lv.niss.gov.ua/content/articles/files/mono_2012-d47ce.pdf

[5] Krakos, Yu. B., Razgon, T. V. (2008). Components of economic security and approaches to their assessment. Aktualni problemy ekonomiky, 3 (21), 12-19.

[6] Ivanyuta, T. M., Zaichkovsky, A. A. (2009). Economic security of the enterprise. Kyiv: Center for Educational Literature, 54.

[7] Sak, T. V. (2015). Diagnosing the level of economic security of an enterprise in the conditions of limited information. Visnik Mykolayivskogo natsionalnoho universytetu im. V. O. Suhomlynskogo, 3, 404-408.

[8] Akhnazarova, S. L., Kafarov, V. V. (1985). Methods of optimization of experiment in chemical technology. Moscow: Higher school, 328.

[9] Fishburne, P. (1z978). Theory of utility for decision-making. Moscow: Science, 352.

[10] Moroz, V. S., Moroz, S. V. (2010). Estimation of the living standard of the generalized Harrings ton function. Visnik Khmelnytskogo natsionalnoho universytetu, 3 (5), 53-58. 